\title{
HACIA UN DERECHO TRANSNACIONAL DE CONTRATOS
}

\author{
Joaquín Emilio Acosta Rodríguez
}

Le damos un cordial saludo a los apreciados e ilustres colegas de la mesa. Que se me permita expresar mi sincero agradecimiento a la profesora Mónica Fernández por ofrecerme generosamente este espacio para poder compartir con ustedes las ideas que veo siguen siendo objeto de debate: si es conveniente o no implementar una reforma al Código Civil.

Sobre su relación con el fenómeno de la constitucionalización, que se me permita entonces partir de una necesidad: frente al debate que se daba entre los profesores Morgenstein y Echeverry (sobre la viabilidad y conveniencia de mantener intacto el Código Civil frente a las nuevas realidades culturales y económicas, políticas y, en general, antropológicas), ya la sala civil de la Corte Suprema de Justicia se hace un eco, un clamor que vienen elevando profesores como Bonivento. Si bien el Código Civil es una obra de filología admirable, producto del genio humanista de uno de los más grandes intelectuales que haya parido la América Latina (el profesor Andrés Bello), habría que preguntarse si esa es la finalidad de un código: rendirle un homenaje a un grande de las letras, o responder a necesidades materiales de la vida social.

Habría que preguntarse si el Código Civil aprehende de manera adecuada realidades como la industrialización, la postindustrialización, la sociedad de consumo, la globalización económica y de todos los órdenes. El hecho es que para la sala civil de la Corte Suprema de Justicia y un sector de la doctrina patria, se debe repensar y replantear al menos la interpretación de nuestras instituciones milenarias.

¿Qué ha venido aconteciendo en el ámbito foráneo? Para poder aclarar la razón de ser del título de mi conferencia, valdría la pena evocar un poco la sexología. Para un sexólogo está claro que es un error confundir a un intersexual con un transexual: son realidades muy diferentes, según su objeto de estudio. De manera análoga, mal se

6 Abogado de la Universidad Santo Tomás de Colombia. Especialista en Derecho Comercial y Magister en Derecho Privado de la Universidad de París II (Panthéon-Assas). Doctor en Derecho de los Negocios de la Universidad de Burdeos. Ejerce como investigador y docente del Politécnico Grancolombiano. 
puede confundir el Derecho Internacional con el Derecho Transnacional. Ya centrándonos en el ámbito jurídico, el Derecho Internacional es principalmente el resultado de las convenciones y demás acuerdos que se celebran entre sujetos de Derecho Internacional, principalmente los Estados.

Por el contrario, el Derecho Transnacional es un neologismo acuñado por un gran jurista estadounidense: el profesor Philip Jessup; cuya aportación ya ha tenido un ámbito y un alcance más allá de las fronteras estadounidenses. Así la academia europea (y especialmente la academia francesa) acogen el término "transnacional" como una nueva modalidad de lo jurídico.

¿Cuál sería la particularidad propia del Derecho Transnacional? Mientras que el Derecho Internacional es el producto de los acuerdos principalmente entre los Estados (como ya lo indicara), en el Derecho Transnacional se edifica el denominado pluralismo jurídico: la pérdida del monopolio estatal de la producción de la normatividad jurídica; en donde la comunidad de comerciantes ha venido creando sus propias reglas. El fenómeno no es reciente: ya en la Edad Media lo atestigua la famosa Ruta de la Seda: ese circuito mercantil que importaba a Europa la famosa tela china que consumían el Papa, el emperador, los reyes, y, en general, la aristocracia occidental. La solución a los conflictos generados a raíz de tal tráfico generaba una desterritorialización de la regla aplicable: la importación de la seda y otros productos provenientes de las Indias Orientales hizo que migrantes de Flandes, Francia, Suiza o de la Liga Hanseática, se radicaran en el territorio asiático. Estas personas no se sentían identificadas con la normatividad propia del territorio y, por lo tanto, se empezó a crear una normatividad mercantil propia que poco tenía que ver con el territorio en el cual se dirimían los conflictos. Esta nueva realidad que se llamó en su momento la lex mercatoria, recuerda ordenamientos tales como el de la FIFA. Ustedes saben que por razones de imparcialidad cuando una final se celebra entre Alemania y Brasil, el árbitro no puede ser de ninguno de estos dos países. De manera colateral, la normatividad que se aplica no puede ser parcial con ninguno de los Estados participantes. En consecuencia, los reglamentos FIFA se han venido creando a través de un ejercicio comparatista, en donde se toman los países que más representatividad y liderazgo han venido teniendo en el mundo del fútbol (Inglaterra, Alemania, Brasil, Argentina, etc.); de todos estos países se toman partes, extractos de sus reglamentaciones y a través de un ejercicio 
comparatista se va haciendo un experimento ecléctico donde cada solución (el fuera de lugar, el tiro desde el punto penal, lo que iría a pasar si se llega al empate técnico, etc.) inspira decisiones a través de un proceso de mestizaje que va a crear un producto que no es absolutamente original, pero sí tiene un margen de novedad. El reglamento de fútbol FIFA es tan poco parecido al reglamento alemán como al reglamento inglés, por razones de neutralidad. Lo mismo pasaba entre los comerciantes medievales.

Entonces, los usos y prácticas mercantiles de Flandes se entremezclaban con los de la Liga Hanseática y demás regiones europeas con marcada presencia mercantilista. Esa labor de mestizaje fruto de una concepción comparatista ha venido generando su impronta: de ahí que la denominación medieval haya inspirado la expresión acuñada en la segunda mitad del Siglo XX: nueva lex mercatoria. Este tipo de prácticas han sido reiteradamente evocadas por instituciones tales como la Cámara de Comercio Internacional de París. No sobra recordar que tal concepto fue impulsado por profesor Berthold Goldman en Francia. Así, un litigio mercantil que se va a ventilar ante un tribunal de arbitramento internacional exigirá miembros que conozcan las prácticas $\mathrm{y}$, en general, fuentes jurídicas de las naciones a que pertenecen los sujetos del litigio... pero al mismo tiempo con una visión imparcial y cosmopolita, en la medida de lo posible. Es decir, las mismas necesidades que impulsaron la promulgación de los reglamentos FIFA. De esta manera, los árbitros designados van a buscar un producto normativo neutro; elaborado a partir del mestizaje y de las soluciones comparatistas.

Esta concepción innegablemente se basa en las soluciones jurídicas elaboradas en la Edad Media, al menos en aquellos casos que desbordaban el estricto marco nacional de referencia. $Y$ consideramos que no es únicamente en tales casos donde se evidencia el eclecticismo y mestizajes dogmáticos: toda creación intelectual (desde la más encumbrada filosofía hasta el arte) toma como base un pasado, a pesar de que se vea como una nueva creación y realidad.

Estas ideas iban a acabar en un producto que ha inspirado mucho al Derecho Transnacional de contratos, y es el denominado Uniform Commercial Code (Código Uniforme de Comercio de los Estados Unidos). Como ustedes muy bien saben, la unión americana es un sistema federal. Por lo tanto, cuando hay comercio transfronterizo o interestatal (especialmente desde la costa este hasta la costa oeste) hay necesidad de uniformizar las soluciones jurídicas, 
pues cada Estado tiene su propia normatividad mercantil contractualista.

Ustedes han visto en las películas como el criminal, cuando cruza los límites del condado logra que la policía del Estado se tenga que detener porque no tiene (decimos inadecuadamente) jurisdicción; cuando, en realidad, carece de competencia para cruzar el límite estatal. Para ello es menester la intervención del $\mathrm{FBI}$, la única policía interestatal que tiene competencia para cruzar el límite al interior de cada Estado de la unión federal. De igual manera se han creado las leyes federales; sin embargo, el fenómeno de la codificación permeó Estados Unidos y por esa razón se decidió promulgar un código uniforme de comercio para toda la unión estadounidense7.

El "Andrés Bello" en este caso, el líder de la comisión redactora en lo académico (no me refiero al plano político) era el profesor Karl Llewellyn. Este académico es uno de los principales exponentes del realismo jurídico norteamericano quien, en virtud de sus múltiples inquietudes, fue profesor investigador en Alemania. Fruto de este tipo de perspectivas, Llewellyn hizo lo que solamente un genio (porque principalmente son los genios y los dementes quienes se atreven a tanto) es capaz de forjar. Hasta ese momento (y tal realidad tiene mucho que ver con la observación del profesor Echeverri en su conferencia) se entendía que la tradición anglosajona y la tradición romanista eran como el agua y el aceite, no se podían mezclar. Sin embargo, el Código Uniforme de Comercio de los Estados Unidos articula la herencia jurídica británica (que subyace a la tradición estadounidense) con instituciones propias del Derecho románico germánico (por ejemplo, instituciones tales como la buena fe). De ahí que el actual Derecho anglosajón (no solo el estadounidense) contemple hoy nociones como la good faith. Igualmente, el tema del fair play ha venido permeando las instituciones mercantilistas y contractualistas anglosajonas. Tal mestizaje ha venido impactando al hemisferio occidental.

Tradicionalmente se ha enseñado que detrás de todas las guerras está una mujer. Cuando dejamos los prejuicios de género y nos adentramos en una correcta aproximación histórica, verificamos que, en realidad, quien se encuentra detrás de todas las guerras es el interés económico; usualmente

7 Desde luego, el peso e impacto de tal tipo de códigos en los EEUU es muy diferente al que se observa en los países de tradición romanista. Por ello, se ha señalado que el UCC ni es código, ni es uniforme. 
de corte mercantil. Por eso, el comercio es un factor de progreso; pero, al mismo tiempo, un factor riesgoso. Debido a ello, la ONU tiene una comisión dedicada a las normatividades mercantilistas incluyendo el ámbito contractual. Al interior de la ONU encontramos la CNUDMI (Comisión de las Naciones Unidas para el Derecho Mercantil Internacional).

Una de las funciones que tiene esta comisión es proponer modelos legislativos acordes con el Siglo XXI, la era posterior a las guerras mundiales: el siglo del universalismo de los Derechos Humanos, y también el siglo de la globalización8. Por ello, tal comisión se dedica a reunir académicos renombrados a nivel internacional, fomentar el diálogo en aras de que lleguen a acuerdos mínimos, en este caso respecto al tema mercantilista. Fruto de tales consensos lo constituyen documentos tales como las leyes modelos y las guías legislativas. Se trata de propuestas dirigidas a los órganos legislativos del planeta, consistentes en la legislación más adecuada para determinados temas comerciales. A manera de ejemplo en el ámbito colombiano, tenemos la ley 527 de 1999, norma basada en una guía legislativa: en efecto, la ley de comercio electrónico colombiano adopta no pocas propuestas de la CNUDMI. Si bien, se ha creído que la tradición romanista y la anglosajona son incompatibles, gracias al avance norteamericano hoy se les ve más bien en un plano de complementariedad: fruto de las nuevas tendencias se va a redactar la famosa convención de Naciones Unidas sobre compraventa internacional de mercaderías. En efecto, la compraventa sigue siendo el contrato más importante y así continúa siendo un referente para la materia contractualista. Por lo tanto, y a partir de los productos que estamos evocando, se hizo un régimen acorde con las necesidades mercantiles; de las cuales muchos pensamos que no solamente sirven para el régimen de compraventa internacional, sino igualmente para el ámbito interno, en donde tales instrumentos son más acordes a las nuevas realidades que la legislación decimonónica.

El profesor Echeverri, con esa vehemente defensa que hizo del Código Civil, me recuerda a Jean Carbonnier. Profesora Aude, yo no sé usted qué opina de una frase famosísima de este ilustre compatriota suyo (me permito traducirla libremente al castellano) quién decía que la verdadera Constitución de Francia es su Código Civil, más que la propia Constitución Francesa. Recordemos que, en 2016, Francia hizo su reforma al régimen de prescripción, de obligaciones $y$, en general, a la columna vertebral de su Derecho

8 Teniendo presente que a lo largo de la historia se han verificado múltiples globalizaciones. 
Privado... entre otras razones, ipara adaptar tal reglamentación a los imperativos de la Constitución de la V República francesa!

Ese "nuevo" Código Civil francés es el heredero de los proyectos de Código Civil europeo, código europeo de contratos y todas estas propuestas de creación supranacional; las cuales tratan de atender fenómenos contemporáneos tales como la globalización, la sociedad de consumo o la postindustrialización. Esto me hace referirme al debate que el profesor Echeverri planteaba al profesor Morgestein con mucho rigor (Carbonnier es una de las grandes leyendas del Derecho Civil). Sin embargo, frente a la sentencia del Decano Carbonnier respecto a la función del Código Civil como verdadera Constitución de Francia (articulándola con la pregunta que el profesor Echeverri le hiciera al profesor Gual respecto al origen de la ley), estimo pertinente evocar el artículo sexto de la Declaración Universal de los Derechos del Hombre y del Ciudadano, el cual estipula que la ley es la expresión de la voluntad general (entiéndase, la voluntad del pueblo). Tal concepción es la heredera de la filosofía de las luces que implementaron los revolucionarios franceses. Sin embargo, en una decisión calificada como un hito por el presidente Zagrebelzky (expresidente de la corte constitucional italiana), el Consejo Constitucional francés en el año 85 profirió una decisión que constituye un cambio en la tradición legalista del país galo, pues aclaró que la ley es la expresión de la voluntad popular... ¡siempre y cuando dicha ley respete la Constitución!

Gracias a una elemental interpretación a contrario de la anterior providencia, tenemos entonces que cuando la ley no es conforme con el marco constitucional, tal tipo de norma no puede entenderse como la expresión de la voluntad del pueblo. Esto por una sencilla razón: porque es igualmente voluntad del pueblo que la Constitución sea norma de normas. Entonces, hay ahí una base democrática que constituye una alternativa a la problemática que el profesor Echeverry acertadamente planteaba frente a la relación que hay entre democracia, legalidad, normatividad constitucional y soberanía popular.

Estos productos han venido marcando una nueva concepción que no constituye una revolución frente a la tradición civilista, pero sí constituyen una evolución. Todo este debate que se ha venido planteando me recuerda cuando Aristóteles (que fue discípulo de Platón), se alejó de la escuela de su maestro. Ustedes saben que Aristóteles estudio unos 20 años en la academia de Platón; posteriormente fundó el Liceo, 
y empezó a analizar críticamente las teorías de su maestro. Hubo voces como la del discípulo heredero de la rectoría de la Academia, que señalaban a Aristóteles elegantemente como un traidor; la réplica de Aristóteles me parece que tiene mucha validez para el actual debate académico: Aristóteles replicó: "soy amigo de Platón, pero soy más amigo de la verdad". Yo trataré de parafrasear a Aristóteles para decir que yo soy amigo del Código Civil, soy amigo de Jean Carbonnier, pero soy más amigo del Derecho y de la justicia.

La misión del Derecho no creo que sea rendirle culto al pasado: los seres humanos tendemos a olvidar las cosas deslucidas del tiempo pretérito y quedarnos con los recuerdos agradables. Esta predisposición quizás nos ha permitido idealizar una sociedad clásica (el Siglo de Oro de Pericles, El Siglo de Oro de Augusto), pero fue al poco de la muerte de Pericles cuando Sócrates democráticamente fue condenado a muerte. Tales realidades demuestran que la democracia como el mismo Sócrates y su discípulo Platón lo enseñaban, debe ser replanteada. A su turno, el denominado Siglo de Oro romano fue el que vio las rebeliones de un guerrillero llamado Espartaco (famoso en la actualidad, gracias a Hollywood) sin olvidar la rebelión de Viriato, las guerras civiles, la ejecución de los hermanos gracos por la cuestión social... tales referentes forzosamente evocan la primera conferencia de hoy. Recuerden los conceptos de usus-fructus o abusus del Derecho romano, que permitían que un pater familiae pudiera hacer con su esclavo lo mismo que podía hacer con sus hijos o con su esposa (violencia impune). Hoy a nadie se le ocurre pensar que como en la Antigua Roma se aceptaban los juegos de gladiadores, hoy tendríamos que resucitar esa institución.

Y miren ustedes como la misma Corte Constitucional (que es acusada de ir en contra de la usanza) se amparó en la tradición para legitimar la tauromaquia. En este punto, creo que valdría la pena (junto con la concepción que hace el profesor Echeverri de la constitucionalización del Derecho), evocar la sentencia C-491 de 2000. Dicha sentencia retoma otro concepto de constitucionalización (estableciendo, más bien, una consecuencia pragmática de lo que implica tal concepto): el deber que tiene todo juez de la República (noten ustedes el término) de reinterpretar la ley a la luz de los principios y valores constitucionales.

Tal planteamiento implica entonces el deber de cambiar la concepción misma del Derecho. Aquí hay una realidad que deberíamos recordar: la razón de ser de la Constitución de 1991, que se inscribe en el denominado Constitucionalismo Transnacional, que se inspira directamente del denominado nuevo constitucionalismo latinoamericano. Recuerden que no solamente en Colombia, sino en 
El Salvador, Honduras, Nicaragua, Perú, Brasil, Venezuela o Bolivia se han promulgado nuevas cartas que inspiraron a la Constituyente de 1991.

¿Cuál fue el primer país latinoamericano que dio el primer paso a este esquema de culto a los Derechos Humanos, la creación de un tribunal constitucional, o el valor normativo supremo de la carta? Chile. En efecto, la Constitución chilena de 1980 (promulgada en plena dictadura de Pinochet) fue consecuencia del cuestionamiento a una de las últimas dictaduras que ha contemplado el cono suramericano. Se verifica entonces que el detonante que impulsó el nuevo constitucionalismo latinoamericano fue el agotamiento ante el totalitarismo y el endémico desconocimiento de los derechos fundamentales.

¿Y de dónde se inspiraron los chilenos? Del fin de la dictadura de Franco, en España, en el año de 1978. En efecto, cuando muere Franco (célebre en la historia por su cercanía con Hitler), su testamento militar fue traicionado; y de esta manera, España pudo hacer su tránsito a la democracia constitucional.

Luego entonces, es el modelo español el que inspiró al modelo chileno, el cual a su vez inspiró el modelo latinoamericano, Colombia incluida. ¿Y cuál fue el referente de los españoles para este nuevo modelo? La constitución portuguesa de 1976, la cual se basó en la Constitución Francesa de 1958, mediante la cual se promulgó la Vème République (Quinta República), así como el Estado constitucional en el país fundador del legicentrismo moderno. Los franceses, por su parte, se inspiraron de la Ley Fundamental alemana del año 49. Ha de recordarse que esta norma de normas se promulgó por presión del mundo libre, para impedir que la barbarie hitleriana se repitiera. De igual manera, los alemanes se inspiraron de la Carta de las Naciones Unidas (también denominada Carta de Derechos) del año de 1948.

Es un escenario común reconocer que para mejor entendimiento del Derecho Civil colombiano, debemos hacer un comparativo con el Derecho Civil chileno; correlativamente, tal reconocimiento nos remite a la dogmática francesa, como lo estaba explicando la profesora Denizot. Lo mismo puede predicarse de la Constitución de 1991, por las razones ya expuestas. Tal método ha sido denominado "originalismo genealógico". Si se encuentra fuera de toda duda que el constituyente de un país se inspiró de una(s) carta(s) de derechos extranjeras: ¿No conviene que el intérprete oficial tenga 
presente el sentido asignado en tales latitudes a los textos constitucionales de referencia? $Y$ este originalismo constitucional colombiano no debe detenerse en el caso alemán. En efecto, los alemanes se inspiraron del caso italiano, luego de que la dictadura de Mussolini fuese derrocada en las condiciones conocidas por todos. Fue en tal contexto que se promulga la constitución italiana de 1947 (y así, podemos remontarnos una vez más a la Constitución de la IV República Francesa de 1946, esa carta de convivencia entre los antiguos miembros de la resistencia y del régimen colaboracionista nazi de Vichy...). De esta manera, nos podemos remontar a la constitución austríaca de 1945. No para seguirlas fielmente, sino ver en el contexto histórico los "añadidos" de las constituciones europeas más recientes, frente a las más antiguas; y de esta manera identificar la "tendencia transnacional constitucionalista".

Luego, la idea de que debemos interpretar la ley a la luz de los valores y principios constitucionales no fue un invento original ni arbitrario de la Corte Constitucional colombiana. Tanto en el contexto latinoamericano como en el caso europeo, podemos remontarnos al fallo Lüth de 1958, ya que tal providencia establece la misma doctrina: en adelante la normatividad civil (y en general, toda ley) deberá ser interpretada a la luz de las normas constitucionales (el fallo Lüth se consigue en castellano, y se puede descargar gratuitamente de internet).

Yo creo que las mismas razones que han exigido volver a pensar el BW (Código Civil holandés), el BGB (Código Civil alemán) o el código francés. La necesidad de adaptar este particular régimen no solo a las realidades socioeconómicas, sino a los nuevos valores constitucionales también exige una nueva concepción del Derecho Civil y, en general, privado colombiano. En efecto, el clásico lus Civile romano era ajeno al Estado Social de Derecho. Este modelo es, a su turno, fruto de la doctrina social de la iglesia; y en general, de la denominada cuestión social: en Francia tal lucha política conducirá a la promulgación de la III República francesa. En tal contexto, la Universidad de Burdeos, tenía entre su nómina docente al padre de la sociología francesa (el profesor Émile Durkheim) y su copartidario jurídico, el profesor Léon Duguit. Este último publicó una obra que no ha sido traducida al castellano: "Les transformations générales du droit privé depuis le Code Napoléon" (Las transformaciones del Derecho Privado desde el Código de Napoleón). "Código Napoleón" es el nombre cariñoso que se le da en Francia a su Código Civil. La idea nuclear es que el Estado Social de Derecho obliga a repensar el Derecho Privado, matizando su individualismo. De ahí que Louis Josserand haya sistematizado la secular teoría francesa del abuso del Derecho: para adaptar el individualismo milenario del Código Civil a 
las exigencias jurídicas del Estado Social desde el advenimiento de la República liberal en los años 30 (ya casi un siglo de ello), se promulgó en Colombia el Estado Social de Derecho... y todavía no hemos querido entender que esa reforma constitucional exige repensar el Derecho Privado todo, y no solo el Derecho de contratos, o el Derecho de personas.

Hoy por hoy, para mentes normales es fácil entender que la distinción que hacía nuestro Código Civil originario entre hijos matrimoniales y extramaritales es inconstitucional. De igual manera, el culto individualista, el culto del "sálvese quien pueda" (heredero de la fisiocracia francesa), ese capitalismo salvaje ya está mandado a recoger por nuestra Constitución de 1991. Esa misma óptica es la de la jurisprudencia alemana, o francesa; nuestros profesores de Derecho Civil rinden culto místico al principio de autonomía de la voluntad privada y su hermano siamés: libertad contractual (dejaré de lado el debate en torno a la naturaleza jurídica de ambos conceptos, considerando que, al menos, hoy son sinónimos).

No se nos olvide que la buena fe también es un principio constitucional. Como si ello fuera poco decir, debe anotarse que la prohibición de abuso del derecho en Francia no tiene rango constitucional... pero en Colombia sí, como claramente lo señala nuestro numeral primero del artículo 95 superior... y como dice el mismo profesor Echeverri, también tiene rango normativo supremo la prohibición de abuso de posición dominante. Y ya que queremos rendirle culto al Código Civil, resulta imperioso recordar que este estatuto consagra el principio de interpretación del efecto útil: "El sentido en que una cláusula puede producir algún efecto, deberá preferirse a aquel en que no sea capaz de producir efecto alguno" (Artículo 1620, Código Civil colombiano). De esta manera, la mayoría de hermeneutas jurídicos aceptan que corresponde al operador jurídico el procurarle un efecto útil a una disposición normativa, descartando cualquier interpretación que niegue eficacia al texto interpretado. En consecuencia, en virtud de tal principio interpretativo, debemos dar un efecto útil a las normas constitucionales; que ya vimos constituyen producto del constitucionalismo transnacional.

La posición jurídica del profesor Echeverri, quien cuestiona nuestra jurisprudencia constitucional (el colega interpelado me confirmará) es concordante con la del profesor Fabricio Mantilla de la Universidad del Rosario, quien es un ácido crítico de la constitucionalización. En consecuencia, 
también debemos evocar a profesores de la Universidad Nacional quienes también abogan por el originalismo interpretativo (hacer Derecho Comparado con los sistemas que inspiraron al nuestro). Bajo tales dinámicas, por ejemplo, se entiende que las sentencias moduladas colombianas, corresponden a los fallos bajo reserva de interpretación proferidos por el Consejo Constitucional francés. En efecto, del Derecho Transnacional se entiende que no solamente hay que hacer control de constitucionalidad de las leyes, sino también control de constitucionalidad de la interpretación que hacemos de las leyes. En efecto, ya Diderot (el padre del Enciclopedismo francés) nos enseñó que es preferible tener buenos jueces a tener buenas leyes: los buenos jueces corrigen las malas leyes, mientras que las buenas leyes son pervertidas por los malos jueces.

Por esa razón, el tema de la interpretación legal debe ser objeto de control constitucional. Ya para terminar, simplemente volvemos a la sentencia que evocaba el profesor Echeverri, entendiendo que esa es la dinámica que se ve en el constitucionalismo alemán, tan estudiado por la academia española o francesa. De esta manera, se verifica que las sentencias proferidas aquí en Colombia se inscriben en la línea jurisprudencial de Alemania, por no decir Francia. La reforma al Código Civil francés, como la reforma al Código Civil alemán u holandés, sirve para adaptar no solamente los códigos a los valores constitucionales, sino también a los valores supranacionales desprendidos del Derecho Europeo. Tal armonización constituye un ejercicio más complejo. Así las cosas, les invito a efectuar una especie de "doble click" estilo Google Maps: de esta manera ampliamos nuestra perspectiva, y vemos que las realidades que se están dando en nuestro país no son un invento exótico del tribunal constitucional patrio, sino que se inscriben en un fenómeno que ya es imparable.

Yo quiero recordar que los tribunales constitucionales no solamente se dan en Europa o América Latina, sino también en Egipto, Sudáfrica, Corea o Tailandia... y son estos tribunales los que han emancipado a la mujer, los que han venido reivindicando la salvaguarda del orden ecológico... para citar un caso local y actual, como ustedes vieron, también al asunto de las aletas de tiburón. (¿Cuántos tiburones hay que sacrificar para obtener las 5,5 toneladas ya comentadas?, ¿será que tal medida es conforme con el desarrollo sostenible?). Este tipo de retos no estaban en los hombros de los romanos; en los nuestros, sí. Yo, ya estoy viejo: yo no voy a ver la debacle inminente de las futuras generaciones muriéndose de sed. Ustedes y la generación de mi hijo, quizás sí.

Si nosotros seguimos protegiendo la autonomía empresarial con los valores del Código Civil, contemporáneo a la época del 
capitalismo que se denominó salvaje (condenado por la misma Iglesia Católica); en menos de 40 años las reservas ecológicas se van a agotar... y créanme que morirse de sed por falta de agua (producto del fracking y de las nuevas formas de explotación económica) no es nada agradable.

Así las cosas, ya no solamente se trata de un tema de agenda social: es de salvaguarda de la vida de nosotros, de la especie humana. Películas sobre el tema (desde "El día que la Tierra se detuvo" hasta los documentales de Leonardo DiCaprio) abundan sobre tal problemática. Repito, no es un tema de agenda social, es de supervivencia de nuestra especie; luego entonces a mí me parece que sí es importante adaptar el Derecho a la nueva realidad. No importa la técnica (yo no soy experto en técnica legislativa) sea por vía de reforma legal, sea por vía de cambio jurisprudencial. Amparándonos en los principios constitucionales, hemos de adaptarnos a desafíos desconocidos por los romanos o por la figura de Andrés Bello. Resulta innegable que nadie se baña dos veces en el mismo río, como decía Heráclito de Éfeso. Así como el Derecho de Familia de hoy, no es el Derecho de ayer (porque ya no estamos en la era del patriarcado); el Derecho de la empresa de hoy bajo la égida de la responsabilidad social, no puede ser como el Derecho del pasado. Estamos en la época de la función social de la propiedad, o la responsabilidad social de la empresa. 